\title{
The Psychology of Creativity: A Critical Reading
}

\section{Vlad Petre Glăveanu}

Aalborg University, Denmark

E-mail address:vlad@hum.aau.dk

ARTICLE INFO

\section{Keywords:}

Creativity theory

Creativity research

Crisis

Definition

Units of analysis

\section{Article history:}

Received 17 October 2013

Received in revised form 1 February 2014

Accepted 7 March 2014

ISSN:

DOI: 10.15290/ctra.2014.01.01.02

\section{A B S TRACT}

The psychology of creativity is nowadays a thriving field of investigation, but also a discipline in crisis. This is the premise for the critical reading of past and present work within this area proposed here. The presentation follows the typical headings of a research article, beginning with a consideration of research questions, definitions and their operationalization, as well as units of analysis, and continuing with reflections on sample and method, discussion of theory and practical implications. At each step, questions are raised about current practices and implicit assumptions in order to help us develop a stronger psychology of creativity in the decades to come. In the end, six main points are placed on a hypothetical agenda for future (creative) creativity research. In this sense, a critical reading is actually the first step in the process of being constructive and calling for increased awareness and responsibility in relation to the future of the discipline.

The psychology of creativity is certainly a discipline that began the new millennium as a blooming area of study, supported by more than a century of theorising and a marked growth in research, particularly after the 1950s. There is a lot of confidence expressed today in the accumulation of findings and the continuous expansion of the field (see Runco \& Albert, 2010, for a historical overview). But there are also cautionary voices that warn against increased fragmentation and dispersion (Hennessey \& Amabile, 2010), signs of chaotic rather than convergent growth. While we can all agree that creativity studies are certainly developing (and one needs only to consider the number of handbooks and journals emerging in previous years, the present journal subscribing to this ascending trend), a vital question needs to be asked: developing towards what? It is my aim here to raise and explore this central question for our discipline in the form of a critical reading of past and present work. Without trying to overstate my conclusions regarding the current state of affairs, a careful exploration of this area has led me to believe that the psychology of creativity is close to a crisis, although its signs might not be perceived 
by many academics working within the field. And this is precisely what makes this 'crisis' more pervasive and difficult to overcome. It is my hope that, opening a debate about where we are and where we are going in terms of creativity research can exorcise concerns that I know other colleagues share (for other reflective accounts see Pope, 2005; Sawyer, 2012) and help us develop a constructive dialogue that will make the psychology of creativity stronger and better equipped to continue its growth in the decades to come.

Before starting the discussion though, it is important to include a few disclaimers. First of all, this is not intended to be a comprehensive review of the psychology of creativity and those interested in obtaining a state of the art account can consult recent Annual Reviews on this topic (Runco, 2004; Hennessey \& Amabile, 2010). As such, the critical reading I am proposing here is necessarily selective. This leaves (plenty of) room for potential counter-examples and I am the first to acknowledge that the critique developed in the following sections applies to 'mainstream' research (i.e. the type of work welcomed by / published in most journals, handbooks, etc.) and does not capture each and every nuance of the broad creativity spectrum. It is even debatable what constitutes the 'mainstream' as many would either not recognise themselves as contributing to it, as a marker of maintaining their own individuality, or consider it a catchall phrase, too wide to ever be useful. In any case, my hope is that a working definition of current mainstream approaches will emerge from the following presentation, rather than through a pre-set formulation. It is hard to avoid thinking about the psychology of creativity in terms of general trends and more marginal positions. As is often the case, disruption and novelty often come about from the 'periphery' and this paper will bring several examples of this dynamic. I should also note that what I consider here problematic, might well be taken as signs of progress by some readers. In this case, divergence of opinion is actually productive as no one particular researcher holds the uncontested 'truth' over what is the correct path to follow. Pragmatically, it is through the consequences of following certain paths and abandoning others that we get to judge what is worthwhile and what is actually a dead-end.

Finally, this article should not be read as either a personal attack addressed to particular researchers or orientations within the psychology of creativity, nor as a discussion of things that only other people do. I am the first to acknowledge the fact that my own work shows signs of at least some of the questionable practices I discuss below and discovering such connections is not a sign of weakness, but an opportunity to consider future steps more carefully. Necessarily the critique I raise is also partial so I would be very happy to see other contributions to this 'list', either building on or rejecting some of my claims. In the end, the value of this exercise lies in the fact that a deeper reflection 
over implicit and explicit assumptions and practices within the psychology of creativity can never be harmful but, if anything, strengthen our position within psychology and within the social sciences. Being critical is the first step towards being constructive and what better time and place to take this step than in the pages of a brand new creativity journal, a fresh space for dialogue and change within the discipline.

\section{Asking questions: What creativity researchers are curious about}

The first way to get to understand a field is to consider what kind of questions scholars within it are asking, i.e., what they are curious about. A simple exercise in this regard can be to read the titles of articles published by leading journals or consider what kind of research is cited most. If one were to perform this exercise, what surely would emerge is the fact that creativity researchers are curious about plenty of things! From neurological to social aspects of creativity, from its measurements to its uses in various applied contexts, from antecedents to consequences, the questions asked by creativity scholars are indeed impressive. And yet here lies perhaps one problem within the discipline: plenty of divergence and relatively little (constructive) accumulation. We seem to be asking every kind of question about creativity without listening enough to what others are doing or what they have found. Of course, there are several key figures within this area whose work is very often cited and widely known - surprisingly, only a handful of people, considering how wide the range of contributors is - whose scholarship provides a kind of backbone for many studies. Who, for instance, doesn't know Wallas's (1926) famous stages of the creative process, who has not heard about Amabile's (1996) Consensual Assessment Technique, or come across Csikszentmihalyi's (1988) systemic model of creativity? (there are of course many more examples than those cited). But beyond these relatively few common reference points, there is plenty of 'chaotic', uncoordinated knowledge construction, where a lot of what is found either is not read, or not built upon sufficiently. But then again, this is certainly one of the key problems in psychology as a whole, rather than being specific to the psychology of creativity in particular. Still, excessive idea generation without sufficient 'implementation' is not a healthy state of affairs, as any creativity researcher knows.

There is a second aspect to this over-production that makes it even more problematic. Scholars seem to have abandoned the 'big' questions in favour of increasingly specialised inquiries leading them to develop subfields of a subfield (adding small bricks to an existing edifice) rather than contributing to our overall understanding of creativity (consider the edifice itself). For example, in creativity research there is a strong interest in the creative person. Within the person, a componential typology distinguishes between 
domain-relevant skills, creativity-relevant processes, and task motivation (Amabile, 1996). Finally, within motivation there is a multitude of studies that experimentally or correlationally seek to uncover what stimulates intrinsic and extrinsic motivation for the task and with what consequences. All of this sounds rather good and typical for any branch of science, but what is often forgotten is the loop back from one's micro-interest (e.g. the relationship between rewards and intrinsic motivation) to the fundamental question of what 'model' of the creative person this research is supported by and contributes to. In reality, even the most specialised study builds on a massive number of assumptions about what creativity is, what the person is and how it relates to other people, what the person and these other people can do in relation to creativity, and so on. This concern goes beyond simply referencing relevant literature, it refers to the need to make explicit one's paradigmatic assumptions. Side-stepping these kinds of fundamental questions (either because there is no space in an article to say anything about them or because this is not what reviewers would expect one to do) makes a narrow research focus go hand in hand with theoretical short-sightedness. Perhaps there is no better example today than the growing interest shown towards the neuropsychology of creativity, prompted to a great extent by the development of technologies that make the study of the human brain easier. Finding the neurological correlates of creativity is a current fascination, but what this really tells us (or can legitimately tell us) about creativity escapes many researchers engaged in this area of investigation.

This leads me to another common worrying 'symptom' within the psychology of creativity: the method-driven nature of the research. If there is a new research instrument out there, then it needs to be used for the study of creativity or variables assumed to relate to it (e.g. intelligence, personality, knowledge, motivation, and so on). This kind of work involves little theorising as the (real) reason why different aspects are measured and related to creativity comes down to us being able to measure and relate them. Incidentally, this is also how correlational research became so popular within the field, going hand in hand with advances in the psychometrics of creativity. Unfortunately though, this tendency leads (paradoxically) to a decrease in overall research creativity. There seems to be quite a lot of thinking 'within the box' and submitting to an established 'orthodoxy' of either method or school of thought, despite the heterogeneity of the actual topics made reference to above. What is very diverse at the level of particular concerns is surprisingly similar at a meta-level of theory and method. This observation led me, previously, to define three main paradigms within creativity research: the $\mathrm{He}$, the I, and the We (see Glăveanu, 2010a). These points of focus - on the genius, the creative person, and the 
social aspects of creativity - remain visible in today's literature and, depending on the framework one chooses to work within, make easier the formulation of particular questions (and not others), the choice of participants and research design, and the procedures for analysis and interpretation. This is not necessarily bad; the trouble is that researchers adopting any one of these paradigmatic views are often not aware of their metatheoretical choices and their important consequences. In this sense, besides the questions actually formulated in various studies, most of the assumptions underpinning the research remain unfortunately unquestioned. Among them, the strong individualistic ideology (Weiner, 2000) that still dominates the field, even in the social psychology of creativity, and is reflected not only at the level of research questions but also by the very definition of key concepts, including creativity, something I pass on to discuss next.

\section{Definition: Making creativity operational}

In 2004, following a review of the field and its relevance for educational psychologists, Plucker and Beghetto noticed that researchers don't usually bother to make explicit their definition of creativity and, "when a definition of creativity is offered in the literature, it often is prefaced with an 'oh, by the way' tone" (Plucker \& Beghetto, 2004, p. 87). It is not hard to understand why this is the case. First of all, the complexity of creativity as a phenomenon makes any one formulation of what it means (to be creative) difficult, to say the least. In essence, scholars are faced with the unique task of making familiar a process that leads to the production of unfamiliarity. On the other hand, and this can be related to what was mentioned in the previous section, an attitude of unquestioned acceptance is the norm and definitions are either taken from somebody else (the rhetorical appeal to 'ethos') or considered to be implicitly shared by the community. The latter, of course, is not the case. In the end, offering a clear definition makes one vulnerable to criticism, including inquiries into how this definition actually plays into the methodology and the interpretation of the findings. Whatever the reason, the tendency to skip definitional work has been noticed by journal editors and reviewers and today many of them require authors to make explicit their premises (Runco \& Jaeger, 2012). So, when formalised, what is the most common understanding of creativity?

While "the definition and assessment of creativity have long been a subject of disagreement and dissatisfaction among psychologists" (Amabile, 1996, p.19), and approaches to defining creativity vary in important ways (Barron \& Harrington, 1981, p. 441), it is safe to assume that one of the best known formulations of what it means to be creative focuses on products and proposes a two-factor criterion of novelty / originality and value / usefulness / meaningfulness / appropriateness. Certainly there are differences between 
novelty and originality (all original things are - initially - new, but not the other way around), as well as between value at an individual and social level. However, what this basic definition managed was to solve an important empirical problem for psychologists interested in creativity: it gave them a simple formulation that could be made operational and save researchers from a series of difficult questions associated mostly with the creative person and creative process. Moreover, this definition seems to agree to some extent with lay conceptions of creativity since people other than psychologists are inclined to associate creativity with novelty, originality, and value. In fact, creativity is such a great quality to possess that it became used and abused in different milieus, from organisations to schools and political campaigns, to the extent that we run the risk now, through "unthinking repetition", to "make the word seem useless" (Williams, 1961, p. 3). The same unconditionally positive aura seems to have followed creativity into the scientific arena, making it one of the few concepts in science that involve a kind of 'moral' judgement.

And yet, novelty and value (Weisberg, 1993) are in many ways problematic to use. Novelty certainly is not sufficient for something to be called creative and, if adopted, would make all things exemplify creativity (Hausman, 1979) since everything is or has been new at some point. Moreover, for how long do we consider something to be 'new'? Novelty is necessarily temporal and the saying that 'novelty wears off' is not just a metaphor. This is why most turn to originality, or the 'distance' between the old and the new, as a real criterion for creative work. Here again, other important questions (rarely asked in practice) need to be raised: "what constitutes a truly original idea? How different does it need to be from other ideas to be 'original?'” (Runco, 2007, p. 379). In the end, nothing is truly original in the absolute sense of the word since, as we know, creative products don't emerge out of thin air, but out of the (re)combination of whatever exists. In this regard, novelty and originality need to be evaluated in relation to a socio-cultural background. And this is even more the case with usefulness or value. Useful for whom and when would be the key interrogation here. A quick historical inquiry can immediately show us that some great creators and creations did not start by being appreciated until others were ready to understand them and the reverse is also true: people and things 'lose' the label of being creative all the time (otherwise history books would be expanded beyond what is possible to hold between two covers). But isn't there a risk also in reducing value to societal value? This ends up contributing to the effective exclusion of everyday life creative acts, including the creativity that takes place in the classroom (Cohen \& Ambrose, 1999).

The above is simply an exercise in unpacking further what we mean by novelty, origi- 
nality, and value, something that more researchers should pay attention to in their own studies. A contextualisation of the classic (by now) definition of creativity is greatly needed, even if it only takes the form of: "The creative work is a novel work that is accepted as tenable or useful or satisfying by a group in some point in time" (Stein, 1953, p. 311; emphasis added). Furthermore, we need to be open, as well, to alternative formulations. One central limitation of what we have discussed here is that it 'locates' creativity at the level of the creative product (which can be an object, an idea, a type of performance, etc.), although it is people who actually create, use and appreciate this product. It would be safer thus to say that creative products are not novel and useful per se but evaluated as such within self - other relations (creator and peers, audiences, critics, etc.). A novel criterion of creativity was proposed, for example, by Jerome Bruner (1962), who advocated for defining creative acts as acts that produce 'effective surprise'. Acknowledging the difficulty of operationalising this notion, Bruner nonetheless concluded that effective surprises "seem rather to have the quality of obviousness about them when they occur, producing a shock of recognition, following which there is no longer astonishment" (Bruner, 1962, p. 18). Consequently, they involve not only product and cognition but also emotions, subjectivity, and the social environment.

Alternatives such as these receive little, if any attention and, in fact, one of the usual ways of making creativity operational for research is by associating it with divergent thinking, "probably the second most common definition of creativity" (Cohen \& Ambrose, 1999, p. 11). Creativity scholars are well aware of the fact that divergent thinking is not synonymous with creativity (Runco, 2007) but, because it is considered to tell us something relevant about at least the cognitive processes involved in creating, it has become one of the golden standards of the discipline (although, of course the methodological toolkit of creativity studies is broader than divergent thinking tests). The whole edifice of psychometric creativity testing, following Guilford's (1950) foundational input, is mainly built around divergent thinking tasks and this long tradition is not about to change any time soon. And this despite repeated calls for expanding such a narrow view and increasing the ecological validity of our approach. Even one of the towering figures of creativity testing, Ellis Paul Torrance, the father of what is arguably one of the most used batteries in the field, considered that "creativity is almost infinite. It involves every sense - sight, smell, hearing, feeling, taste, and even perhaps the extrasensory. Much of it is unseen, nonverbal, and unconscious" (Torrance, 1988, p. 43). So, we can legitimately ask, how is this experiential and ontological richness of creativity as a phenomenon ever contained in tasks like 'please generate as many uses as possible for a brick'? 


\section{Analytical cuts and units of analysis}

The work of defining and making a concept operational are part of a larger process of considering it analytically and, therefore, scientifically. The act of analysis is necessarily one of 'violence' towards the reality at hand, since it is grounded in segmenting the whole into smaller pieces, simplifying it in the process, very often choosing what pieces are more important and disregarding the rest. This analytical exercise typically results in clear and distinguishable 'units of analysis', either the smallest / simplest or most appropriate instances of a phenomenon that can be fruitfully studied. One way of uncovering units of analysis in the case of creativity is to actually consider studies and their definitions and focus. This is the kind of work Mel Rhodes (1962) engaged in and the typology he proposed remains, to this day, one of the most widely cited in the discipline. The four P's of creativity - person, process, product, press - are more than a conceptual organiser, they are in fact units of analysis for creativity researchers. And indeed, the decades that followed saw scholars subscribe to one or more of these P's and locate their studies within them. A critique of the model and a rewriting of this typology was recently proposed elsewhere (Glăveanu, 2013); it is based on a central limitation associated with any analytical 'cut' performed on a otherwise unitary phenomenon: it results in separate, static, disjointed elements and ignores interactions and overlaps. In the words of Barron (1995, p. 32):

“(...) the triadic division [product - process - person] is itself perhaps an oversimplification. There is not always a hard and fast line among the three aspects that in practice have come to mark off areas of emphasis in the psychology of creativity. Many products are processes, and many processes are products. And a person is both a product and a process. Each is in a sense 'a field within a field' - a field that never closes, for we really are talking about open systems, delineated for purposes of abstraction as product, process, and person."

In an effort to recover this sense of unity and coordination between the four P's, we need to also consider what such an analytical abstraction leaves behind or reduces in the process. One clearly dismissed and yet crucially important element is time. Gruber and Wallace (1999) argued for including duration within the definition of creativity and nobody can deny that creative work involves a lot of time to mature, to be expressed, to be explored, etc. Moreover, there is a growing field of studies in the discipline looking at creative expression and development and sharing the assumption that "creativity is quintessentially a developmental matter" (Feldman, 1999, p. 170). And yet, if we take only the example of developmental studies, most of them are cross-sectional rather than longitudinal, which means they actually focus on states rather than processes (see Valsiner, 1997). This is 
even more the case when the emphasis is placed on the creative product, again outcome rather than process. What is more worrying, "psychologists who study creativity have usually separated ideation, divergent thought, and insight on the one hand and execution, implementation, and performance on the other" (Sawyer, 1998, p. 11). Furthermore, they take idea generation as the domain proper of the psychology of creativity and thus reduced considerably the temporal dimension of what it means to create. Preparatory stages (that can be traced back far into the ontogenetic history of the person), the physical action of making, the use and reactions to what is made, etc. are secondary for a psychologist equipped mainly with divergent thinking tests.

Idea generation is also typically considered an 'intra-psychological' activity, something that brings the individual to the fore and sends the environment to be background or even out of the picture. It often doesn't even include more than the individual's cognitive faculties. In contrast, Bruner once remarked that "the act of a man creating is the act of a whole man" (Bruner, 1962, p. 18). What is there 'inside' the whole person? Gruber (1998) proposed a dynamic perspective that articulates three loosely coupled subsystems: knowledge, purpose, and affect. This more comprehensive perspective leaves room for synchronicity and also a-synchronicity in development. Gardner (1994) actually believed that the latter is the real characteristic of creative individuals, "an unusual configuration of talents, and an initial lack of fit among abilities, the domains in which the individual seeks to work, and the tastes and prejudices of the field" (Gardner, 1994, p. 146). This observation is useful as it pushes towards an extension of our unit of analysis from person to 'person in context'. Recent decades have witnessed a resurgence of social psychological studies of creativity (Hennessey, 2003), despite some negative reactions see (Runco, 1999; Weisberg, 1993) from scholars who consider the social approach misleading because it introduces too much 'noise' into an otherwise neat intra-psychological equation. The persistent obsession with the individual becomes manifest even in studies of group creativity where the analytical focus is often on individual processes and contributions rather than emerging action (Sawyer, 1997). The study of one-off interactions is also preferred in experimental studies of group creativity to the more cumbersome and time-consuming longitudinal analysis of collaborative work. Under these circumstances, it should come as no surprise that "much evidence in the literature [points to the fact that] groups may inhibit intellectual activity or optimal performance” (Paulus \& Nijstad, 2003, p. 4).

Finally, another analytical 'cut' is performed in relation to objects and even the body of the creator him or herself. If the atemporal, asocial mind is what researchers tend to focus on as a primary locus of creativity (atemporal and asocial mostly for the convenience of a more 'parsimonious' scientific analysis), then this mind also seems to float unsup- 
ported by eyes and ears, by hands and legs, by the world of material artefacts 'out' there, ready to be used and transformed. The Geneplore model (Ward, Smith \& Finke, 1999), for as useful as it is to distinguish between two main, inter-related stages of creative production - the generation of ideas and their exploration, - says very little about the physicality of the environment or the embodied nature of creative work. And yet, ideas are never ethereal, they have a verbal, written, pictorial, bodily expression. Even when people think, and all the more when they create, there is movement, and speech, and use of tools like pens and paper, etc. A vision of distributed creativity (Glăveanu, 2014) is long overdue in the discipline, one that would place creative work not outside the mind, but inbetween mind and environment, self and other, the psychological and the material. Such a project can take inspiration from relatively recent developments in cognitive science and particularly the work of scholars such as Ed Hutchins (1995). Creativity, just like cognition, needs to be studied and theorised more 'in the wild', outside the cognitive or computational models of psychologists and within the real world, in the very contexts of its production and evaluation. It is there where to create means not to think but to do before, during, and after getting ideas, to touch, and see, and be touched and seen in return.

In conclusion, proceeding analytically in the psychology of creativity is a requirement for any scientific investigation. But there are analytical outcomes (or 'cuts') that can help and others that are detrimental to our understanding and possibilities for practical action. An often harmful distinction is, in my view, that between idea generation and idea implementation whenever the two are disconnected from each other. Making sure they have a strong hold on what they think is the proper domain of psychology, ideas and/in minds, and thus considering idea generation the true 'moment' of creation, psychologists managed to break creativity from innovation, learning, and perception. On the way, they also incidentally made creativity theory and research much less interesting and relevant for practitioners and colleagues from other disciplines. For instance, there is a growing community today in management and organisational studies that prefers the term innovation and considers it "the practical application of creative ideas" (Westwood \& Low, 2003, p. 236). While getting the idea is important, researchers in this field rightfully argue that seeing it through is actually what matters most. Similarly, if creative ideas come to those who are prepared for them, this long period of preparation is depicted as a less exciting or creative (yet necessary) stage of learning and mastering a domain. But since when is learning ever divorced from creativity? How is it possible to learn without changing both the content of learning and oneself as a learner? The same can be said about the creator - audience 'gap'. If our analytical focus is only on the person of the creator, defined as the author of 
new and valuable work, we are missing out perhaps the most important part of creativity: the reconstruction of this work, symbolic and material, when perceived and used by others. Without this ability to make existing things new by reworking our understanding of them and relation to them, the Mona Lisa would simply be today an old, well-crafted painting.

\section{Sample and method}

There are two main methodological paths taken by researchers working within the psychology of creativity. The first involves historical and present day case studies of important creative achievements while the second employs either psychometrics and laboratory studies for the investigation of creative problem solving (see Weisberg, 1993). These approaches can be used to answer a variety of questions regarding creative people, from uncovering their personality profile to studying cognitive processes. In fact, individual-differences research into the creativity of ordinary individuals proceeds by either selecting a sample of highly creative people and then comparing their profile to that of the 'normal' population, or simply applying both creativity and cognition / personality scales and examining their correlation within an average population (Amabile, 1996). Whatever way is chosen, there are important questions in relation to each practice that typically go unanswered or unasked. For instance, based on what criteria do we choose highly creative individuals and how do we take into account the fact that such criteria are always relative to a certain time and group of reference? And even when the individuals chosen seem to be universally acclaimed for their work (e.g. Newton, Da Vinci, Einstein), what makes us sure that information about their profile tells us something relevant about mundane forms of creativity?

These kinds of questions address one important assumption made by creativity researchers - the existence of a creativity 'continuum' connecting great achievements (at one end) to everyday creative expression (at the other). While similarity in terms of basic underlying cognitive processes (Ward, 2001) is generally assumed, clearly there are both contextual and psychological differences between creative acts (for a suggested typology see Glăveanu, 2012a). This observation raises the fundamental issue of achieving a balance in our investigations of creativity between understanding generality and specificity or, at a methodological level, applying nomothetic versus ideographic research principles. On the one hand, we have the anonymous and universal subject of psychometric or experimental testing, inter-changeable and 'average' with regard to many variables. On the other, the intensive, in-depth investigations of the unique creative individual (Gruber, 2005), bringing to the fore his or her experience of creating within a dynamic context. 
There are then other methods, such as historiometry, which try to make uniqueness measurable and comparable by applying "quantitative methods to archival data about historic personalities and events to test nomothetic hypotheses about human thought, feeling, and action" (Simonton, 1999a, p. 815). Although seemingly combining the 'best' of both paths described above, and offering us generalisable information about highly creative individuals, historiometry falls prey to the limitation of any radical quantification which is excessive abstraction of the individual from its complex social context

One way in which researchers attempted to bring this social and cultural context back into the psychology of creativity is represented by the widely used Consensual Assessment Technique (CAT) applied to the evaluation of creative outcomes. Proposed by Teresa Amabile as a central methodological companion to her 'social psychology of creativity', CAT is based on the assumption that "a product or response is creative to the extent that appropriate observers independently agree it is creative" (Amabile, 1996, p. 33). In this way, creativity assessment becomes grounded in intersubjective agreement about the world and thus relative to the people and context of this agreement. However, the emphasis on convergence and consensus manages to challenge the very premise of CAT. If evaluation is supposed to be contextual, that means that it can and should diverge across different settings (based on who is evaluating creative outcomes and when this evaluation takes place). This should lead us to more consistent efforts to uncover how creativity assessment varies between different communities and at different moments in time (for a methodological proposal, see Glăveanu, 2012b). And yet, by reducing the options of what an 'appropriate observer' is to expert judgement and making this panel of experts homogeneous, findings from the application of CAT indicate, again and again, that experts, in the absence of a formal definition, tend to agree about what is more versus less creative. Paradoxically, this conclusion reinforces the view of creativity as an almost 'objective' quality of the product rather than a function of the context.

Overall, it is safe to say that the psychology of creativity is still very much driven by psychometrics, the ethos of measurement that actually got the field started in the first place and helped psychologists turn the mysterious, almost mystical, capacity to create into something that people can identify, assess, predict. What is rarely interrogated however is the ideology of psychometric assessment and the fact that it is fundamentally based on the premise that creativity is "a mental trait that can be quantified by appropriate measurement instruments" (Mayer, 1999, p. 452). Joining forces with experimental studies of creativity, the two made quantification and control the golden standard for 'good' science and 'good' research. The marginalisation of qualitative studies is both dis- 
concerting and questionable (including the current decision of the Creativity Research Journal to publish only quantitative research). The quantification of creativity, as also argued above, goes hand in hand with its simplification, to the point of not recognising anymore the phenomenon that we are trying so hard to understand. How can we ever relate back, in a meaningful way, people's capacity to generate ideas on demand, about things they might have no or little interest for, to their everyday activity and experience as creative agents? How can we stop reading creativity 'backwards', in terms of its results, and start exploring it 'forwards', in terms of its movement (Ingold \& Hallam, 2007, p. 2)? How can we observe more closely the microgenesis of creativity, its emergence within moment to moment activity and interaction? Fundamentally, not by means of psychometrics as currently defined and practiced.

\section{Discussion and/no theory}

All the issues raised above contribute to one of the most problematic aspects faced by the psychology of creativity today: an increasing accumulation of research findings without being matched by theory-building. This doesn't mean that all or even most studies are atheoretical since, as we know, it is a requirement of having work published to perform at least a minimal literature review and place one's study within existing scholarship. The issue is that the theoretical ambitions in most cases are rather limited. It might be that the age of grand theories of human psychology has passed and we are left with mediumlevel theorising (Karwowski, 2012), but what exactly can we hope to achieve by creating theories for a single branch or a single tree and missing the whole forest? There are many constraints of space, time, aim, etc. that work against adopting a broader view and making bolder theoretical claims but, if we are to keep the psychology of creativity thriving in the decades to come, we need such thinking. What is more, we need to acknowledge the importance of 'grand theories' for organising and guiding our research and, most significantly, we need to acknowledge that we are guided by such theories and paradigmatic views even when we think we are not.

This might sound controversial but it is my belief that the first decades of the last century were, on the whole, much more creative in terms of theoretical thinking than what followed as the discipline grew bigger and bigger. If quantity is not necessarily related to quality, then being productive as a research community doesn't necessarily mean being original and innovative. Starting the 'official' history of the discipline around the 1950s and referring constantly to Guilford's APA Presidential speech as a turning point serves to obscure the fact that creative thinking about creativity happened long before (not to mention outside psychology). Thinkers like John Dewey, Sigmund Freud and James Mark Bald- 
win, among many others, might not be immediately seen as creativity scholars but they should be! If their efforts were aimed at constructing large theoretical frameworks, like pragmatism or psychoanalysis, this doesn't mean they assigned creativity a secondary position. On the contrary, a careful reading of Dewey's (1934) Art as Experience reveals one of the most fascinating accounts of creativity as action (see Glăveanu, 2013b), while Baldwin's (1903) developmental studies made not only adults but children as well, at once, imitators and inventors. For Freud, every child at play behaves like a creative writer since "he creates a world of his own or, rather, rearranges the things of his world in a new way which pleases him" (Freud, 1970, pp.126-127; in original 1908). Most importantly, to understand his claim (just as any by Dewey, Baldwin, etc.) one needs to situate it within the complex system of thought elaborated by the author. Freud's parallel, in this case, is not gratuitous. It draws on psychoanalytic theories of play and phantasy, of repression and sublimation, of the interplay between a creative (Eros) and destructive (Thanatos) principle embedded within our psychology. Is this viewpoint still legitimate, is the whole theoretical edifice solid? This is of course open for debate but, what cannot be contested is the impact of psychoanalysis on our thinking and research, within and beyond the psychology of creativity (we can consider, for instance, its relevance for research on creativity and pathology).

The conclusion to be drawn from here is that theory building is not reduced or reducible to understanding, for example, the fourth grade creativity slump with the help of psychometric investigations (as useful as this type of research is in its own right). These findings and middle-level models cannot float around, unsupported, they need to be 'located' somewhere within a conception of what creativity is in relation to what being a person is, or what it means to live within a society and culture. Many will probably argue that the latter are not to be addressed by creativity researchers and, indeed, one cannot reasonably be expected to first construct a theoretical framework of the magnitude of pragmatism or psychoanalysis and only then be able to answer specific questions regarding creative work. This is not the point. Grand theories already exist, and they are to be found not only inside psychology (think for instance about Bergson's work on creative evolution or Bourdieu's concept of the habitus); it is a matter of knowing these theories and making the effort to understand and work with or against them. This is possible and has been previously done, for example in relation to Darwin's theory of evolution (see Simonton's, 1999b, inquiry into whether creativity is a process of blind variation and selective retention). There are also several examples of broad frameworks or typologies for understanding creative action and they include, among others, the Propulsion Theory of Creative Lead- 
ership (Sternberg, Kaufman \& Pretz, 2003) or the Amusement Park Theory of Creativity (Kaufman \& Baer, 2004). We need more initiatives like these if the field is to make a real contribution to scientific debates and practice, rather than run around in circles using the same methods and concepts over and over again.

\section{Practical implications: To be continued...}

'Why isn't creativity more important to educational psychologists?' was the question asked by Plucker and Beghetto (2004), surprised not to find more creativity research cited and used by colleagues working in the field of education. This type of problem is neither new nor easy to solve (see also Urban, 1991; Houtz \& Krug, 1995). It largely derives from the weaknesses and limitations discussed above in relation to theory and method within the psychology of creativity. There is little practitioners from education and other applied fields, like business or art, can do with a conception of creativity as a mental property or with measurement that focuses on product and potential instead of actual practices. Unfortunately, although creativity researchers do argue for the practical importance of their work, they fall short of their promise by being very vague about their advice. When creativity articles do have a section (or rather a paragraph) on practical implications, these tend to simply reiterate why the general topic proposed or the findings are interesting or important. What educators or managers should do with them is anyone's guess...

To understand how creativity research can become more relevant we need to return to a theoretical consideration. Before trying to enhance creative expression, the crucial question to ask is whether creativity can indeed be educated. There are very few who would disagree with this premise and, historically, the psychology of creativity took shape based on the assumption that psychologists can do something about creativity, helping people to either become or remain creative (Guilford, 1950). However, the long-term fascination with inherited abilities and personality traits paradoxically runs counter to this aspiration. As Amabile eloquently observed:

"There is not much that can be done about innate abilities and personality characteris-

tics. Furthermore, although cognitive skills necessary for creative performance can be developed, this process normally occurs over relatively long periods of time. By contrast, social environments influencing creativity can be changed easily and can have immediately observable effects on performance" (Amabile, 1996, pp. XVI-XVII).

The theme of how to design environments conducive for creative performance has been one of the most important topics for practically minded creativity researchers. And yet, once more, the theoretical perspective adopted to consider both person and environment 
is not always the most productive as it typically imposes a strict and ultimately false separation between person and world, treated as two units of analysis instead of one integrated system. If the environment is simply made up of positive and negative stimulations, according to an old behaviourist schema, then the creative output becomes a mere response conditioned by different independent and mediating variables. Unfortunately, the everyday practice and experience of creating in the classroom, at the office, or in the art studio doesn't conform to this binary model of person interacting with environment. It relies instead on the two being inter-dependent (Glăveanu, 2011; Tanggaard, 2013), which means that creative individuals exist within a social and material environment and this environment exists within the person as well. Moreover, studying creative performance in artificial settings and with the help of unfamiliar tasks can only distort our understanding of how creativity actually emerges outside the lab. Unfortunately, the focus in group creativity studies of brainstorming, for instance, has been on setting up one-off sessions where people are called to generate ideas together, ignoring the fact that idea generation is not a one time achievement but a continuous process embedded within long-term collaboration (Montuori \& Purser, 1997). Being creative virtually on demand or among strangers, a usual paradigm of research in this area, cannot possibly be very insightful for people working with real life teams and organisations (Moran \& John-Steiner, 2003, p. 82).

There is also the reverse of being overly concerned with control in experimental designs and trying to produce knowledge for practitioners in applied fields and this danger is embodied by the ' $X$ steps to' approach (or the toolbox approach; Purser \& Montuori, 2000). Corporate training is full nowadays of pseudo-scientific conclusions and tricks of the trade coming from supposed creativity studies. Their main fault, apart from the dubious nature of the research that supports them, is the implicit assumption that one size fits all and that what works within one context will probably work in another, more or less similar one. Just as there is no single theory that can meaningfully cover all the dimensions of what it means to create, there certainly is no one formula for how to be creative in practice. Either not being concerned with the practical implications of one's work or overpromising and simplifying an otherwise complex reality are dead-ends on the path to more respectability among communities of practitioners. If the psychology of creativity is to make an impact in real life, it needs to start its investigations from real life and not keep them (completely) inside the laboratory or testing room. Turning the social, organisational, and educational arenas into an open laboratory is a clear necessity for academics, even if this means going out of one's comfort zone and challenging current ways of thinking and doing research. 
Finally, what we need to become more and more aware of as a community is the fact that our research has important consequences for society, even when these consequences are unintended. This is because scientific findings do feed into lay representations (see Moscovici, 1984) of what 'creativity' or the 'creative person' is. In this process, they articulate with existing ideologies and systems of belief about human agency, the power of institutions, and the political and economic system. It is not hard to notice, for instance, that our current ideas about creativity and the emphasis on social, often economic, value, relate to the ethos of consumerism (as creative and continuous production stimulates increased consumption) and capitalism (stimulating private initiatives, competition, and property over one's creations) and, ultimately, support discourses of growth and development strongly endorsed by 'First World' countries. The consequences of such thinking for other parts of the world, as well as the environment, are becoming more and more visible today and both academic and practitioners invested in the study of creativity can no longer ignore the global debate they themselves contribute to through their research. In this sense, critical thinking should be at the core of research and stimulate an ongoing reflection on impact and social responsibility.

\section{Future directions}

After considering questions, definitions, analytical units, sample and methods, theoretical and practical contributions, it is time to end, as most articles do, with future directions. Just that, instead of considering what is commonly included under this heading, I will propose here a possible future agenda for creativity research. I started by claiming that the psychology of creativity is experiencing a crisis, despite the growing number of studies, journals, books and handbooks, etc., or the obvious appeal this type of research has for the general public. From this perspective, opening a debate about the existence and nature of the 'crisis' can only be an opportunity to reflect on current practices and directions of research and, indeed, look towards the next decades. My critique was admittedly broad in scope and I reaffirm the conviction that what has been mentioned above doesn't apply to each and every piece of research in the literature. Moreover, several of what I consider limitations might be taken as signs of progress by others, particularly progress in the direction of a more positivistic study of creativity. And indeed, the advancement of psychometrics or experimental designs, for example, did make significant contributions. My aim is not to downplay one methodology or another (as each has its own virtues and weaknesses), nor is it to claim that nothing of value has been achieved in the decades since the 1950s (thus throwing out the baby with the bathwater). The point is that we need to build more systematically on what we have achieved as a field and, at the same 
time, do so in a critical manner. Being critical in this case is not a sign of scepticism but the first step towards being constructive and more engaged.

My own work, aiming to establish a cultural psychology of creativity (Glăveanu, 2010a,b), has focused on several of the limitations mentioned above and tried to tackle old habits of thought in relation to creativity, the creative person, process, product, and environment. This discipline, still situated at the periphery, has the potential of leading us towards new and exciting directions for theory and research. It can also make the study of creativity more inter-disciplinary and help us get out of the 'box' of what psychology considers valid and useful. It is my deep belief that scientific questions should not be formulated from particular disciplinary positions but focus on the actual topic or phenomenon under investigation. The real world is not neatly and conveniently segmented into parts ascribed to psychologists, to sociologists, to biologists, etc. We are the ones creating our own segments of interest and when they are too narrow (like an exclusive focus on person or product) it is not only the big picture that we are missing but also the chance to engage in dialogue with people who share similar concerns. At the same time, the cultural psychological approach is only one among other valid approaches to creativity and our task is to consider how to put these perspectives into dialogue instead of creating new theoretical and methodological 'boxes' for them.

Based on the points made here about the current state of the psychology of creativity, there are a few take-away conclusions for future research. Many of these will seem obvious, but it is taken together that I believe they can make a powerful impact on the field and help it move forward:

1. Ask bold, new, and surprising questions. It might seem at times, considering the extent of the literature, that most of the key questions have been asked already and one can only add an extra variable or test a common hypothesis on a new sample. This perception is wrong: it is the 'old' questions that have been asked again and again, truly innovative ones are still waiting to be raised.

2. Reflect on definitions, do not simply take them for granted. And this includes of course the definition of creativity. It is perfectly justifiable to use classic formulations that point to novelty, originality, value, etc. but do so in a critical manner. In particular, see how definitions relate to the methodology used and constrain or facilitate data analysis and interpretation.

3. Challenge traditional units of analysis. While zooming in on the individual is legitimate in cases where the research question refers to individual variables, we should be careful to avoid letting this unit of analysis - the individual mind - drive our questions. 
Many interesting interrogations actually push the researcher towards challenging traditional analytical 'cuts' that separate person from environment, product from process, and so on. It is important in these cases not to abandon such questions or constrain them by applying the usual methodologies, ready at hand.

4. Look for unique, interesting samples and develop new methods. Related to the previous point, it is always important to remember that, when a certain method (for data collection or analysis) doesn't seem to exist, we can invent it and/or draw inspiration from other disciplines in the process. In fact, methodological exchanges are as important as theoretical ones and a cross-disciplinary practice that unfortunately is rare so far. Also think about going beyond psychology students and acknowledged creators as participants. The world is full of people who, due to their social or personal circumstances, have something interesting to tell us about creativity.

5. Build theory, don't just cite it. The literature review and discussion sections are not simply an occasion to cite the works you are expected to cite, but should be treated as an opportunity to position your concern and your findings within a broader context. In describing this context one needs to reflect not only on what theories explicitly state, but also on what they implicitly entail about creativity, cognition, culture, and so on. Contributing to the paradigmatic debates within the discipline is more valuable than adding another citation within a micro-field of inquiry.

6. Think practically about your conclusions. Creativity research is more than a scientific or academic exercise. Creative action is part of the life of people and their activity, so its study is unavoidably an intervention that has the potential to shape both, a potential not to be wasted!

These are six fairly general principles for the agenda of future (creative) creativity research. The list is of course open to additions. The main aim, as argued throughout this article, is to build more systematically on what we have collectively achieved as a scientific community and, at the same time, do so in a critical and reflective manner. Just like creativity, the discipline itself requires dialogue and collaboration and its outcomes are not the product of individual thinking but of joint efforts. As a community, creativity researchers should take a good look at their own studies and think about how their conclusions concerning creativity can be used to revitalise the field. In the end, knowledge about creativity is, or should be at least, a creative outcome. How this outcome comes about and can be put to better use remain open questions for us all.

\section{REFERENCES}

Amabile, T. M. (1996). Creativity in context. Colorado: Westview Press. 
Baldwin, J. (1903). Mental development in the child and the race: Methods and processes. Second edition. London: Macmillan \& Co.

Barron, F. (1995). No rootless flower: An ecology of creativity. Cresskill: Hampton Press.

Barron, F. \& Harrington, D. (1981). Creativity, intelligence, and personality. Annual Review of Psychology, 32, 439-476.

Bruner, J. (1962). On knowing: Essays for the left hand. Cambridge: Belknap Press.

Cohen, L. \& Ambrose, D. (1999). Adaptation and creativity. In M. Runco \& S. Pritzker (Eds.), Encyclopedia of creativity, 1(1) (pp. 9-22). San Diego: Academic Press.

Csikszentmihalyi, M. (1988). Society, culture, and person: a systems view of creativity. In R. Sternberg (Ed.), The nature of creativity: Contemporary psychological perspectives (pp. 325-339). Cambridge: Cambridge University Press.

Dewey, J. (1934). Art as experience. New York: Penguin.

Feldman, D. H. (1999). The development of creativity. In R. Sternberg (Ed.), Handbook of creativity (pp. 169-186). Cambridge: Cambridge University Press.

Freud, S. (1908/1970). Creative writers and day-dreaming. In P.E. Vernon (Ed.), Creativity: Selected readings (pp. 126-136). Harmondsworth: Penguin Books.

Gardner, H. (1994). The creators' patters. In M. Boden (Ed.), Dimensions of creativity (pp. 143-158). London: MIT Press / Badford Books.

Glăveanu, V. P. (2010a). Paradigms in the study of creativity: Introducing the perspective of cultural psychology. New Ideas in Psychology, 28(1), 79-93.

Glăveanu, V. P. (2010b). Principles for a cultural psychology of creativity. Culture \& Psychology, 16(2), 147-163.

Glăveanu, V. P. (2011). Creativity as cultural participation. Journal for the Theory of Social Behaviour, 41(1), 48-67.

Glăveanu, V. P. (2012a). Habitual creativity: Revising habit, reconceptualizing creativity. Review of General Psychology, 16(1), 78-92.

Glăveanu, V. P. (2012b). A multiple feedback methodology for the study of creativity evaluations. Journal of Constructivist Psychology, 25(4), 346-366.

Glăveanu, V. P. (2013a). Rewriting the language of creativity: The Five A's framework. Review of General Psychology, 17(1), 69-81.

Glăveanu, V. P. (2013b). Creativity and folk art: A study of creative action in traditional craft. Psychology of Aesthetics, Creativity, and the Arts, 7(2), 140-154.

Glăveanu, V. P. (2014). Distributed creativity: Thinking outside the box of the creative individual. London: Springer. 
Gruber, H. (1998). The social construction of extraordinary selves: Collaboration among unique creative people. In R. Friedman \& K. Rogers (Eds.), Talent in context: Historical and social perspectives on giftedness (pp. 127-147). Washington: American Psychological Association.

Gruber, H. (2005). The creative person as a whole: The evolving systems approach to the study of creative work. In E. Gruber \& K. Bödeker (Eds.), Creativity, psychology and the history of science (pp. 35-104). Dordrecht: Springer.

Guilford, J. P. (1950). Creativity. American Psychologist, 5, 444-454.

Hausman, C. R. (1979). Criteria of creativity. Philosophical and Phenomenological Research, 40(2), 237-249.

Hennessey, B. (2003). The social psychology of creativity. Scandinavian Journal of Educational Research, 47(3), 253-271.

Hennessey, B. A. \& Amabile, T. (2010). Creativity. Annual Review of Psychology, 61, 569 $-598$.

Houtz, J. C. \& Krug, D. (1995). Assessment of creativity: Resolving a mid-life crisis. Educational Psychology Review, 7(3), 269-300.

Hutchins, E. (1995). Cognition in the wild. Cambridge, MA: MIT Press.

Ingold, T. \& Hallam, E. (2007). Creativity and cultural improvisation: An introduction. In E. Hallam \& T. Ingold (Eds.), Creativity and cultural improvisation (pp. 1-24). Oxford: Berg.

Karwowski, M. (2012). Middle and grand theorizing in the psychology of creativity. Creativity and Leisure: An Intercultural and Cross-disciplinary Journal, 1(2), 109-114.

Kaufman, J. C. \& Baer, J. (2004). The Amusement Park Theoretical (APT) Model of Creativity. The Korean Journal of Thinking \& Problem Solving, 14(2), 15-25.

Mayer, R. (1999). Fifty years of creativity research. In R. Sternberg (Ed.), Handbook of creativity (pp. 449-460). Cambridge: Cambridge University Press.

Montuori, A. \& Purser, R. (1997). Social creativity: The challenge of complexity. Translation of Le dimensioni sociali della creatività. Pluriverso, 1(2), 78-88.

Moran, S. \& John-Steiner, V. (2003). Creativity in the making: Vygotsky's contemporary contribution to the dialectic of development and creativity. In R.K. Sawyer et al. (Eds.), Creativity and development (pp. 61-90). Oxford: Oxford University Press.

Moscovici, S. (1984). The phenomenon of social representations. In R. Farr \& S. Moscovici (Eds.), Social representations (pp. 3-70). Cambridge, UK: Cambridge University Press. 
Paulus, P. \& Nijstad, B. (2003). Group creativity: An introduction. In P. Paulus \& B. Nijstad (Eds.), Group creativity: Innovation through collaboration (pp. 3-11). New York: Oxford University Press.

Plucker, J. A., Beghetto, R. A. \& Dow, G. T. (2004). Why isn't creativity more important to educational psychologists? Potentials, pitfalls, and future directions in creativity research. Educational Psychologist, 39(2), 83-96.

Pope, R. (2005). Creativity: Theory, history, practice. London \& New York, NY: Routledge.

Purser, R. \& Montuori, A. (2000). In search of creativity: Beyond individualism and collectivism. Paper presented at the Western Academy of Management Conference, April 8, Kona, Hawaii.

Rhodes, M. (1961). An analysis of creativity. Phi Delta Kappan, 42, 305-311.

Runco, M. (1999). Creativity need not be social. In A. Montuori \& R. Purser (Eds.), Social creativity, vol I (pp. 237-264). Cresskill: Hampton Press.

Runco, M. A. (2004). Creativity. Annual Review of Psychology, 55, 657-687.

Runco, M. A. (2007). Creativity. Theories and themes: Research, development, and practice. Burlington, MA: Elsevier Academic Press.

Runco, M. A. \& Albert, R. S. (2010). Creativity research: A historical view. In J. C. Kaufman \& R. J. Sternberg (Eds.), The Cambridge Handbook of Creativity (pp. 3-19). Cambridge: Cambridge University Press.

Runco, M. A. \& Jaeger, G. J. (2012). The standard definition of creativity. Creativity Research Journal, 24(1), 92-96.

Sawyer, R. K. (1997). Introduction. In R. K. Sawyer (Ed.), Creativity in performance (pp. 1-6). Greenwich, Connecticut: Ablex Publishing Corporation.

Sawyer, R. K. (1998). The interdisciplinary study of creativity in performance. Creativity Research Journal, 11(1), 11-19.

Sawyer, R. K. (2012). Explaining creativity: The science of human innovation. $2^{\text {nd }}$ edition. Oxford: Oxford University Press.

Simonton, D. K. (1999a). Historiometry. In M. Runco \& S. Pritzker (Eds.), Encyclopedia of creativity, vol 1 (pp. 815-822). San Diego: Academic Press.

Simonton, D. K. (1999b). Creativity as blind variation and selective retention: Is the creative process Darwinian? Psychological Inquiry, 10(4), 309-328.

Stein, M. (1953). Creativity and culture. Journal of Psychology, 36, 311-322.

Sternberg, R. J., Kaufman, J. C. \& Pretz, J. E. (2003). A propulsion model of creative leadership. The Leadership Quarterly, 14(4-5), 455-473. 
Tanggaard, L. (2013). The sociomateriality of creativity in everyday life. Culture \& Psychology, 19(1), 20-32.

Torrance, E. P. (1988). The nature of creativity as manifest in its testing. In R. Sternberg (Ed.), The nature of creativity: Contemporary psychological perspectives (pp. 43-75). Cambridge: Cambridge University Press.

Urban, K. K. (1991). Recent trends in creativity research and theory in Western Europe. European Journal of High Ability, 1(1), 99-113.

Valsiner, J. (1997). Culture and the development of children's action: A theory of human development. Second edition. New York: John Wiley.

Wallas, G. (1926). The art of thought. New York: Harcourt-Brace.

Ward, T. B. (2001). Creative cognition, conceptual combination, and the creative writing of Stephen R. Donaldson. American Psychologist, 56(4), 350-354.

Ward, T., Smith, S. \& Finke, R. (1999). Creative cognition. In R. Sternberg (Ed.), Handbook of creativity (pp. 182-212). Cambridge: Cambridge University Press.

Weiner, R. P. (2000). Creativity and beyond: Cultures, values, and change. Albany: State University of New York Press.

Weisberg, R. (1993). Creativity: Beyond the myth of the genius. New York: W. H. Freeman and Company.

Westwood, R. \& Low, D. (2003). The multicultural muse: Culture, creativity and innovation. International Management of Cross-Cultural Management, 3(2), 235-259.

Williams, R. (1961). The long revolution. London: Chatto \& Windus.

Corresponding author at: Vlad Petre Glăveanu, Department of Psychology and Communication, Aalborg University, 3 Kroghstræde St., 9220 Aalborg, Denmark.

E-mail: vlad@hum.aau.dk 